\title{
Column on Telebehavioral Health Education, Training, and Competency Development: Current and Future Impact of the COVID-19 Pandemic
}

\author{
Kenneth P. Drude ${ }^{1}[$
}

Received: 1 September 2020 / Revised: 19 June 2021 / Accepted: 30 June 2021 / Published online: 9 July 2021

(c) The Author(s), under exclusive licence to Springer Nature Switzerland AG 2021

\begin{abstract}
The COVID-19 pandemic in 2020 has resulted in many worldwide rapid and major changes in how behavioral health education, training, supervision, and service delivery are being done and will have significant long-term implications for the future of telebehavioral health (TBH). Mandates for social distancing during the pandemic necessitated urgently changing from in-person forms of education, training, supervision, and service delivery to uses of telecommunications, often with minimal preparation. This column on telebehavioral health education, training, supervision, and competencies presents some examples of how organizations, programs, and practitioners generally successfully adapted and responded to these sudden circumstances. How some of the major barriers to the adoption of telebehavioral services in the USA were quickly changed, and considerations for the future education, training, and service delivery of telebehavioral health are identified.
\end{abstract}

Keywords COVID-19 $\cdot$ Telebehavioral health $\cdot$ Education $\cdot$ Training $\cdot$ Supervision $\cdot$ Videoconferencing

\section{Introduction}

The COVID-19 pandemic crisis that began in 2020 and continues in 2021 has resulted in a global "wake-up call" for behavioral health (BH) professions. It quickly challenged psychiatrists, psychologists, social workers, counselors, and other health professions to change how training and education are done as well as how to continue to provide BH services safely. For many, telehealth was "the right solution" for the delivery of mental health services (Torus et al., 2020).

Telecommunications, primarily videoconferencing, within a matter of weeks replaced much of what was previously in-person services, education, supervision, and training. Although telebehavioral health (TBH) services have been repeatedly shown to be effective alternatives to in-person $\mathrm{BH}$ services prior to the COVID-19 crisis (Hilty et al., 2013; Totten et al., 2016), the provision of telebehavioral health (TBH) services faced numerous preexisting barriers for its

Kenneth P. Drude

kdrude@yahoo.com

1 Kenneth P. Drude, Ph.D. LLC, Dayton, OH, USA adoption, including reluctance and resistance from BH practitioners, educators, payors of services, and regulators (Drude, 2020).

One of the most profound changes in response to the pandemic was the necessity for social distancing, a public health measure to contain and to minimize the spread of and to avoid exposure to the COVID-19 virus. Many behavioral health practices and practitioners providing primarily in-person services were unprepared and suddenly had to discontinue services or quickly find alternatives using telecommunications (e.g., telephone and videoconferencing). Although not reviewed in this column, the impact of the pandemic on the well-being of health care practitioners (Morgantini et al., 2020; Braquehais et al., 2020; Rieckert et al., 2021; Moitra et al., 2021) and their patients/clients added further complexity to responses to the pandemic.

This column reviews some examples of the rapid responses and significant changes made in the education, training, and providing of behavioral health services as a result of the COVID-19 pandemic and discusses there implications and current and future opportunities this presents. 


\section{Responses to the Pandemic}

\section{Changes in Telehealth Barriers}

In response to the COVID-19 pandemic, some US federal government agencies made significant changes in previous regulatory restrictions to the provision of telehealth services that facilitated access to telebehavioral health services. The Office of Civil Rights (OCR) of the Department of Health and Human Services issued a notification that practitioners could temporarily use telecommunication platforms and applications that did not fully comply with the privacy and security Health Insurance Portability and Accountability Act and rules without penalty as long as telehealth services were provided in good faith and obtained informed patient/client consent (Office of Civil Rights, 2020). Another federal agency, the Center for Medicare and Medicaid Services (CMS), issued major changes in telehealth service rules regulating Medicare services reimbursed by CMS, affecting physicians, nurse practitioners, clinical psychologists, and licensed clinical social workers (Center for Medicare and Medicaid Services, 2020). Prior location restrictions of patients/clients at the time of service were changed, allowing for services in their homes, as well as expanding the modes of communications to include telephones. The Department of Justice, Drug Enforcement Agency (Drug Enforcement Administration, 2020), in response to the national declaration of the public health emergency, temporarily permitted the prescription of controlled substances without an inperson medical exam if practitioners used two-way audiovisual telecommunications, complied with applicable state and federal laws, and if it was for "a legitimate medical purpose." Many of these changes were quickly adopted by private insurance companies as well.

In addition to US federal government regulatory changes that provided greater access to TBH services, most US state health professional licensing boards temporarily reduced regulations that restricted interjurisdictional practices. This allowed not only BH services to be maintained for people who suddenly were restricted geographically but also allowed greater flexibility for the supervision of those who were practicing under the authority of a supervisor's license.

Proposed federal legislative changes underway at the time that this column was written included bills in the US Congress to make permanent many of the temporary federal telehealth changes made during the pandemic as well as introducing changes that would strengthen the status of telehealth in health care in the USA (ATA, 2020). In a similar fashion, some state legislation expanding access to telebehavioral health services by private health insurance companies and state health funded plans may be introduced.

\section{Service Providing Organization Responses}

Organizations providing mental health services prior to the pandemic quickly found ways to convert services from inperson to telehealth during the pandemic by using primarily videoconferencing and/or telephone (Perrin et al., 2020; Sharma et al., 2020; Yellowlees et al., 2020). Many of these demonstrated the importance of being flexible and open to change in order to adapt to the sudden changes thrust upon them. New ways of providing education and training, providing supervision and services, rapidly were put into place, requiring new policies, procedures, and protocols. Changes that previously may have previously taken months to bring about often were achieved in a matter of weeks. In some cases, service providing organizations either expanded existing educational materials and offerings or quickly developed them for their practitioners and professionals in training.

A good description of transitioning from outpatient to telehealth psychiatric services is provided by Velázquez et al. (2020). They describe the step by step planning process and implementation that they used to convert in a five-day period from outpatient nonurgent care to telehealth by the psychiatry department at Cambridge Health Alliance. Their is one of the more detailed presentations of how psychiatrists continued providing services in response to the pandemic. The article succeeds in providing “... practical strategies for rapid implementation of telepsychiatry and key takeaways for other health care organizations undertaking similar transformations" (Velázquez et al., 2020).

Professional health member organizations (e.g., American Telemedicine Association, American Psychological Association, American Counseling Association) responded to the pandemic by providing free basic online webinars and/or other resources to its members in telebehavioral health (TBH) practice. Some BH education and training businesses that had already offered TBH training such as Person-Centered Tech and Telebehavioral Health Institute supplemented their online offerings with free introductory TBH webinars.

\section{Individual Practitioner Responses}

Several examples of practitioner surveys, primarily of psychologists after COVID-19, illustrate how TBH practitioners reacted and transitioned to telehealth practice. A survey of registered psychologists in Australia conducted by Downing and Marriott (2020) found that about two-thirds of the survey respondents had used videoconferencing prior to COVID-19 and that the majority were "comfortable" in using it after COVID-19.

A survey of 3015 US psychologists assessing the impact the pandemic on their practices reported that respondents quickly transitioned from in-person services to primarily to 
using telephone, text-based messaging, and videoconferencing (Sammons et al., 2020). Interestingly, 58\% indicated that they felt somewhat or extremely prepared to conduct telepsychology - even though they most likely did not have significant training or education in doing so. The authors recognize this issue by stating "We remain concerned that psychologists may not have adequate information to buttress the belief that they are appropriately prepared to conduct telepsychology competently and with minimal risk to clients and themselves." (Sammons et al., 2020, p.54).

A survey of psychotherapists in North America and Europe, who were primarily psychologists, conducted shortly after the World Health Organization e COVID-19 pandemic declaration, found that psychotherapists with past online experience "... were reasonably positive regarding the switch to online psychotherapy during the pandemic" (Bekes \& Doom, 2020). The authors concluded by emphasizing the importance of psychotherapists obtaining training, peer support, and supervision for telepractice in their dealing with on-going stress and experiences with using videoconferencing.

\section{Educational and Training Responses}

Since many behavioral health practitioners typically had minimal or no telehealth education and training experience in their professional development prior to the pandemic (Cruz et al., 2021; Sunderji et al., 2015; Gluekauf et al., 2018; Hertlein et al., 2021; Hoffman \& Kane, 2014; Perry et al., 2020; Pierce et al., 2020; Sammons et al., 2020), providing and obtaining basic telehealth education to quickly transition to telehealth services were typical responses after COVID-19 by service organizations and practitioners.

Professional health member organizations (e.g., American Telemedicine Association, American Psychological Association, American Counseling Association) responded to the pandemic by providing free basic online webinars and/or other resources to its members in telebehavioral health (TBH) practice. Some $\mathrm{BH}$ education and training businesses that had already offered TBH training such as Person-Centered Tech and Telebehavioral Health Institute supplemented their online offerings with free introductory TBH webinars.

COVDID-19 social distancing requirements halted or drastically curtailed many traditional in-person didactic classes, and in-person supervision and clinical experiences for learners in health professions (e.g., students, trainees, residents, fellows). A number of publications describe creative and alternative ways of providing educational and training experiences since the start of the pandemic that frequently include teaching and supervision using videoconferencing and sharing resources online (e.g., Almarzooq et al., 2020; Atreya \& Acharya, 2020; Chen \& Mullin, 2020; Jumreornvong et al., 2020; Almarzoog et al., 2020; Richards \& DeBonis, 2020; Roberts, 2020).
Some clinical programs and clinics providing training for behavioral health professionals have published descriptions of their experiences in transitioning from in-person to virtual settings. For instance, Hames et al. (2020) identify many of the issues and challenges experienced by psychology training programs when forced to rapidly change from in-person services to telehealth services in response to COVID-19. These include focusing on best practices, not just temporary crisis accommodations, legal and ethical considerations, documentation and recording of services, adapting to telesupervision, managing trainee and supervisor distress, and patient informed consent and privacy. Although the authors seem to minimize the importance of telepractice education and training, they acknowledge that “...it would be important for the field to develop and adopt competencies specific to the practice of telepsychology" (Hames et al., 2020).

A psychology training program at the Virginia Commonwealth University providing in-person psychological services at twelve primary outpatient care sites implemented a telepsychology program in a matter of weeks in response to COVID-19 restrictions (Perrin et al., 2020). Although the program had already planned for the implementation of telepsychology and offered some training in telepsychology prior to the pandemic, their response after the pandemic required quick development of online training and transition of services using telephone or videoconferencing. The increased use of supervision via telesupervision and use of virtual team meetings to provide support for more isolated practice were noted as important changes.

Sharma et al. (2020) describe how a child and adolescent training site in a large psychiatry department and primarily outpatient clinic at Seattle Children's Hospital over a month switched to a home-based telemental health (HB-TMH) virtual clinic. Although about half of the staff previously had some telemental health experience, the changes described in the article in response to the pandemic provide ".... roadmap for establishing a HB-TMH service with focus on rapid implementation" (Sharma et al., 2020, p. 404) for others to consider.

A brief column authored by Yellowlees et al. (2020) summarizes another example of a quick transition from inperson to telehealth services by an outpatient teaching psychiatric clinic at UC Davis Health. The authors present key steps that they took to make the conversion over a couple of weeks and what was learned from the experience. Key steps included having a plan, communicating the plan to all staff, notifying all patients with appointments, ensuring providers have proper equipment and training, and having a short trial period to refine implementation. They identify some of the major challenges and lessons learned such as technology barriers, attention to security and confidentiality, infrastructure, and benefits of having a trial period. 


\section{Current and Future Considerations}

It is important that behavioral health professions consider and apply what has been learned from the COVID-19 experience. For instance, what issues and changes are needed by educational programs, service providing organizations, and individual practitioners for the future of $\mathrm{TBH}$ ?

As an example, Haque (2020) identifies seven major factors organizations need to consider when considering post pandemic telehealth services: how and when both virtual and in-person services will be provided, operational and work flow issues, establishing long-term technical infrastructure, involving staff in future telehealth service planning and service provision, patient needs, financial and regulatory considerations, and planning for evaluating outcomes.

Uncertainty about how long the pandemic will last, its ongoing social and economic impact, and how long the "temporary" legal and regulatory accommodations will last will continue to impede returning to more predictable "normal" routines and lives. A long post pandemic recovery period may be likely, having lasting multiple health, social, political, and economic effects at both individual and population levels. Many of the temporary changes made during the pandemic may continue into the future and remain long term.

Telebehavioral health practices quickly adopted during the pandemic will need to be evaluated, and when appropriate incorporated into how future $\mathrm{BH}$ services, education and training are provided in the future. Although telebehavioral health services will probably be considered more mainstream health care in the future and will be more routinely available (Chin \& Palchik, 2020), it will not be the exclusive mode for providing behavioral health services. Increased uses of hybrid models of service in which virtual and in-person services are both available to patients/clients are likely to be more common, even once pandemic social isolation restrictions no longer exist. Some patients/clients will continue to be better suited for in-person services.

\section{Developing TBH Competencies}

Telebehavioral health competencies encompass a broad range of knowledge, skills, and attitudes needed for TBH practice that go beyond compliance with ethics and laws and knowing how to use technology. Practitioners new to TBH practices since the pandemic are advised to assess their TBH competencies to determine what further training, education, and experience that they may need. Maheu et al. (2019) provide an interdisciplinary TBH framework useful for such a self-assessment. Competency can be viewed as existing on a continuum. Many new TBH practitioners since the pandemic are likely to be at a beginner or novice level of competency and will need further education, training, experience, supervision, or consultation to obtain a proficient level of competency. This includes learning what practitioners in other $\mathrm{BH}$ professions are doing in $\mathrm{TBH}$ and when possible, collaborating with and learning from them (MacMullin et al., 2020). It is incumbent upon TBH practitioners to be familiar and comply with their professional standards and guidelines and best practices relevant to telehealth practice. These are often similar but may differ across professions and countries (Smith et al., 2020).

\section{Institutional Telebehavioral Health Education and Training}

A commentary by Tolsgaard et al. (2020) focuses on a framework for the short- and long-term educational consequences of the pandemic that is helpful to consider in future TBH education and training programs. In response to the pandemic, they recommend educational programs view training and education activities at all levels in terms of choosing what to continue, postpone, adapt, discontinue, or add as well as how to enact those choices. Programs are advised to evaluate both the short- and long-term consequences of those decisions. They further challenge educational programs to "question long standing assumptions about healthcare education long after the pandemic is over."

Educational accrediting bodies for graduate educational programs for health care professions do not include requirements for telepractice competencies in program curriculums. As a result, most graduate health profession program curriculums have little or no TBH components. As Chike-Harris et al. (2021) advocate, educational programs for $\mathrm{BH}$ professions need to incorporate $\mathrm{TBH}$ into their curriculums and provide clinical experiences for professionals in training since TBH has become a more significant and important component of health services.. Such education and experiences by professionals while in training are important for the future use of telehealth by behavioral health professionals. As Pierce et al. (2020) found with psychologists, having prior training in telehealth practice and work in settings that have policies supportive of its use are predictive factors for the use of telehealth practice.

Educational programs need to provide strong administrative support and faculty development to assure that adequate resources are available for TBH learning experiences. Examples of basic introductory TBH educational approaches are beginning to be developed that could be applied by different professions (Maheu et al., 2020; Perle, 2020). 


\section{Licensing Laws and Compacts}

Licensing boards could do more to support and promote telehealth. Regulatory boards in addition to protecting the public by enforcing licensing laws and regulations have a responsibility to educate their licensees about appropriate professional practices, including TBH. They need to provide clear, consistent guidance regarding telepractice expectations to their licensees. Increased adoption of health profession interjurisdictional compacts by state legislature will create a more consistent and accessible telehealth practice environment for future TBH services. It is the author's belief that the pandemic may promote increased support for interjurisdictional compacts among US states that a number of health professions already have (e.g., physicians, nurses, psychologists) and prompt other health professions to develop their own interstate compacts in the future.

\section{Conclusion}

Behavioral health professionals, educational and training institutions, and service providing organizations successfully responded to the COVID-19 pandemic by rapidly replacing in-person services with telehealth services and adapting education, training, and supervision to virtual formats. Reductions in regulatory and reimbursement barriers by governmental bodies and payors of services during this period facilitated this transition. Telebehavioral health services dramatically increased during the pandemic and will continue to be a significant, although not exclusive, mode of service delivery for future mental health services. Greater inclusion of formal TBH education and training of behavioral health professionals is crucial for the future of telebehavioral health.

\section{References}

Almarzooq, Z., Lopes, M., \& Kochar, A. (2020). Virtual learning during the COVID-19 pandemic: A disruptive technology in graduate medical education. Journal of the American College of Cardiology, 75(20), 2635-2638. https://doi.org/10.1016/j.jacc.2020.04. 015

American Telemedicine Association. (2020). ATA applauds Bipartisan House Telehealth Caucus Champions for introducing the protecting access to Post-COVID-19 Telehealth Act to permanently expand use of telehealth. https://www.americantelemed.org/press-releases/ ata-applauds-bipartisan-housetelehealth-caucus-champions-forintroducing-the-protecting-access-to-post-covid-19-telehealth-actto-permanently-expand-use-of-telehealth/

Atreya, A., \& Acharya, J. (2020). Distant virtual medical education during COVID-19: Half a loaf of bread. The Clinical Teacher, 17, 1-2. https://doi.org/10.1111/tct.13185
Békés, V., \& Doorn, K. (2020). Psychotherapists' attitudes toward online therapy during the COVID-19 pandemic. Journal of Psychotherapy Integration, 30, 238-247. https://doi.org/10.1037/ int0000214

Braquehais, M. D., Vargas-Cáceres, S., Gómez-Durán, E., Nieva, G., Valero, S., Casas, M., \& Bruguera, E. (2020). The impact of the COVID-19 pandemic on the mental health of healthcare professionals. QJM: An International Journal of Medicine, 113(9), 613617. https://doi.org/10.1093/qjmed/hcaa207

Center for Medicare and Medicaid Services. (2020). COVID-19 frequently asked questions (FAQs) on Medicare Fee-for-Service (FFS) billing. Updated August 26, 2020 https://www.cdc.gov/ csels/dls/locs/2020/cms_issues_updated_COVID-19_faqs_about_ medicare_billing.html

Chen, C., \& Mullin, J. (2020). COVID-19 can catalyze the modernization of medical education. Journal of Medical Internet Research: Medical Education, 6(1), e19725. https://doi.org/10.2196/19725

Chike-Harris, K. E., Durham, C., Logan, A., Smith, G., \& DuBoseMorris, R. (2021). Integration of telehealth education into the health care provider curriculum: A review. Telemedicine Journal and e-Health, 27(2), 137-149. https://doi.org/10.1089/tmj.2019. 0261

Chin, H. P., \& Palchik, G. (2020). Telepsychiatry in the age of COVID: Some ethical considerations. Cambridge Quarterly of Healthcare Ethics, 24, 1-5. https://doi.org/10.1017/S0963180120000523

Cruz, C., Orchard, K., Shoemaker, E., \& Hilty, D. (2021). A survey of residents/fellows, program directors, and faculty about telepsychiatry: Clinical experience, interest, and views/concerns. Journal of Technology for Behavioral Science, 6(2), 327-337. https://doi. org/10.1007/s41347-020-00164-5

Downing, L., \& Marriott, H. (2020). Mapping Australian psychologists' experiences of telehealth during the COVID-19 pandemic. [White paper] https://www.affectmedia.com.au/wp-content/uploads/2020/ 06/Telehealth-and-Psychology-WhitePaper_2020.pdf

Drude, K. (2020). A commentary on telebehavioral health services adoption. Clinical Psychology: Science and Practice, (Published online January 2020). https://doi.org/10.1111/cpsp.12325

Drug Enforcement Administration. (2020). COVID-19 information page. Retrieved at https://www.deadiversion.usdoj.gov/coronavirus.html

Gluekauf, R., Maheu, M., Drude, K., Wells, B., Wang, Y., Gustafson, D., \& Nelson, E. (2018). Survey of psychologists' telebehavioral health practices: Technology use, ethical issues and training needs. Professional Psychology: Research and Practice, 49(3), 205-219.

Hames, J., Bell, D., Perez-Lima, L., Holm-Denoma, J., Rooney, T., Charles, N., et al. (2020). Navigating uncharted waters: Considerations for training clinics in the rapid transition to telepsychology and telesupervision during COVID-19. Journal of Psychotherapy Integration, 30(2), 348-365. https://doi.org/10.1037/int0000224.

Haque, S. (2020). Telehealth beyond COVID-19. Psychiatric Services, Published Online. https://doi.org/10.1176/appi.ps.202000368

Hertlein, K., Drude, K., Hilty, D., \& Maheu, M. (2021). Toward proficiency in telebehavioral health: Applying interprofessional competencies in couple and family therapy. Journal of Marital and Family Therapy, 47(2), 357-374. https://doi.org/10.1111/jmft. 12496

Hilty, D. M., Ferrer, D. C., Parish, M. B., Johnston, B., Callahan, E. J., \& Yellowlees, P. M. (2013). The effectiveness of telemental health: a 2013 review. Telemedicine and e-Health, 19(6), 444-454.

Hoffman, P., \& Kane, J. (2014). Telepsychiatry education and curriculum development in residency training. Academic Psychiatry, 39 (1), https://doi.org/10.1007/s40596-013-0006-6

Jumreornvong, O., Yang E., Race J., \& Appel, J. (2020). Telemedicine and medical education in the age of COVID-19. Academic 
Medicine, 95(12), 1838-1843. https://doi.org/10.1097/ACM. 0000000000003711 PMID: 32889946

MacMullin, K., Jerry, P., \& Cook, K. (2020). Psychotherapist experiences with telepsychotherapy: Pre COVID-19 lessons for a post COVID-19 world. Journal of Psychotherapy Integration, 30(2), 248-264. https://doi.org/10.1037/int0000213

Maheu, M., Drude, K., Merrill, C., Callan, J., \& Hilty, D. (2020). Telebehavioral health: Foundations in theory and practice for graduate learners, Cognella Inc.

Maheu, M., Drude, K., Hertlein, K., Lipschutz, R., Wall, K., \& Hilty, D. (2019). Correction to: An interprofessional framework for telebehavioral health competencies. Journal of Technology in Behavioral Science. https://rdcu.be/b0351 https://doi.org/10.1007/ s41347-019-00113-x

Moitra, M., Rahman, M., Collins, P. Y., Gohar, F., Weaver, M., Kinuthia, J., Rössler, W., Petersen, S., Unutzer, J., Saxena, S., Huang, K. Y., Lai, J., \& Kumar, M .(2021). Mental health consequences for healthcare workers during the COVID-19 pandemic: A scoping review to draw Lessons for LMICs. Frontiers in Psychiatry, 12:602614. https://doi. org/10.3389/fpsyt.2021.602614

Morgantini, L. A., Naha, U., Wang, H., Francavilla, S., Acar, O., Flores, J. M., et al. (2020). Factors contributing to healthcare professional burnout during the COVID-19 pandemic: A rapid turnaround global survey. PLoS One, 15(9), e0238217. https://doi.org/10. 1371/journal.pone.0238217

Office of Civil Rights. (2020). Notification of enforcement discretion for telehealth remote communications during the COVID-19 nationwide public health emergency. Retrieved from https://www.hhs.gov/ hipaa/for-professionals/special-topics/emergency-preparedness/ notification-enforcement-discretion-telehealth/index.html

Perle, J. (2020). Introduction to telehealth for clinical psychologists: A novel course designed to improve general knowledge and handson expertise with technology-based modalities. Journal for Technology in Behavioral Science, Published Online. https://doi.org/ 10.1007/s41347-020-00147-6

Perrin, P., Rybarczyk, B., Pierce, B., Jones, H., Shaffer, C., \& Islam, L. (2020). Rapid telepsychology deployment during the COVID-19 pandemic: A special issue commentary and lessons from primary care psychology training. Journal of Clinical Psychology, 76(6), 1173-1185. https://doi.org/10.1002/jclp.22969

Perry, K., Gold, S., \& Shearer, E. (2020). Identifying and addressing mental health providers' perceived barriers to clinical video telehealth utilization. Journal of Clinical Psychology, 76(6), 11251134. https://doi.org/10.1002/jclp.22770

Pierce, B., Perrin, P., \& McDonald, S. (2020). Demographic, organizational, and clinical practice predictors of U.S. psychologists' use of telepsychology. Professional Psychology: Research and Practice, 51(2), 184-193. https://doi.org/10.1037/pro0000267

Richards, M., \& DeBonis, K. (2020). Psychiatric training during a global pandemic: How COVID-19 has affected clinical care, teaching, and trainee well-being. Psychiatric Services in Advance Published online. https://doi.org/10.1176/appi.ps.202000
Roberts, C. (2020). How medical education can help in a COVID-19 crisis. The Clinical Teacher, 17, 241-243. https://doi.org/10.1111/ tct. 13183

Rieckert, A., Schuit, E., Bleijenberg, N., ten Cate, D., de Lange, W., de Manvan Ginkel, J., Mathijssen, E., Smit , L., Stalpers, D., Schoonhoven, L., Veldhuizen, J., \& Tappenburg, J. (2021). How can we build and maintain the resilience of our health care professionals during COVID-19? Recommendations based on a scoping review. BMJ Open, 11, e043718. https://doi.org/10.1136/bmjopen-2020-043718

Sammons, M., VandenBos, G., \& Martin, J. (2020). Psychological practice and the COVID-19 crisis: A rapid response survey. Journal of Health Service Psychology, 46, 51-57. https://doi.org/10. 1007/s42843-020-00013-2

Sharma, A., Sasser, T., Gonzalez, E., Stoep, A., \& Myers, K. (2020). Implementation of home-based telemental health in a large child psychiatry department during the COVID-19 crisis. Journal of Child and Adolescent Psychopharmacology, 30(7), 404-413. https://doi.org/10.1089/cap.2020.0062

Smith, K., Ostinelli, E., Macdonald, O., \& Cipriani, A. (2020). COVID-19 and telepsychiatry: Development of evidence-based guidance for clinicians. Journal of Internet Medical ResearchMental Health, 7(8), e21108. https://doi.org/10.2196/21108

Sunderji, N., Crawford, A., \& Jovanovic, M. (2015). Telepsychiatry in graduate medical education: A narrative review. Academic Psychiatry, 39(1), 55-62. https://doi.org/10.1007/s40596-014-0176-x

Tolsgaard, M., Cleland, J., Wilkinson, T., \& Ellaway, R. (2020). How we make choices and sacrifices in medical education during the COVID-19 pandemic. Medical Teacher, 42(7), 741-743. https:// doi.org/10.1080/0142159X.2020.1767769

Torus, J., Myrick, K., Rauseo-Ricupero, N., \& Firth, J. (2020). Digital mental health and COVID-19: Using technology today to accelerate the curve on access and quality tomorrow. Journal of Internet Medical Research-Mental Health, 7(3), e18848.

Totten, A., Womack, D., Eden, K., McDonagh, M., Griffin, J., Grusing, S., \& Hersh, W. (2016). Telehealth: Mapping the evidence for patient outcomes from systematic reviews. Rockville (MD): Agency for Healthcare Research and Quality (US); 2016 June Report No.: 16-EHC034-EF.

Velázquez, P., Gupta, G., Gupte, G., Carson, N. \& Venter, J. (2020). Rapid implementation of telepsychiatry in a safety-net health system during Covid-19 using Lean. NEJM Catalyst. https://doi.org/ 10.1056/CAT.20.0319NEJM

Yellowlees, P., Nakagawa, K., Pakyurek, M., Hanson, A., Elder, J., \& Kales, H. (2020). Rapid conversion of an outpatient psychiatric clinic to a $100 \%$ virtual telepsychiary clinic in response to COVID-19. Psychiatric Services, 71(7), 749-752. https://doi.org/ 10.1176/APPI.PS.202000230

Publisher's Note Springer Nature remains neutral with regard to jurisdictional claims in published maps and institutional affiliations. 